\title{
OBSESSIVE-COMPULSIVE DISORDER WITH AND WITHOUT TICS IN A CLINICAL SAMPLE OF CHILDREN AND ADOLESCENTS
}

\author{
Gregory L. Hanna, M.D., ${ }^{1 *}$ John Piacentini, Ph.D., ${ }^{2}$ Dennis P. Cantwell, M.D. ${ }^{2 \dagger}$ Daniel J. Fischer, M.S.W., ${ }^{1}$ \\ Joseph A. Himle, Ph.D., ${ }^{1}$ and Michelle Van Etten, Ph.D. ${ }^{1}$
}

\begin{abstract}
The purpose of this study was to discriminate subtypes of obsessive-compulsive disorder (OCD) in a clinical sample of children and adolescents. Sixty OCD patients were assessed in two outpatient psychiatric clinics; 15 patients bad a lifetime bistory of tics and 45 patients had no tic history. Interviews were conducted with the patients and their parents by a child psychiatrist using the Children's Yale-Brown Obsessive Compulsive Scale (CY-BOCS). The symptom checklist of the CY-BOCS was used to categorize obsessions and compulsions. Discriminant function analysis was used to compare the two groups in their symptomatology. There was no difference between the two groups in seven obsession categories. However, there was a significant difference between the two groups in seven compulsion categories. Ordering, hoarding, and washing compulsions were more common in those with no tic history. The results indicate that tic-related OCD may be differentiated from non-tic-related OCD early in life by the presence or absence of certain compulsive symptoms. Depression and Anxiety 16:59-63, 2002. ๑ 2002 Wiley-Liss, Inc.
\end{abstract}

Key words: obsessions; compulsions; tics; phenomenology; childhood, adolescence

\section{INTRODUCTION}

$\mathbf{O}$ bsessive-compulsive disorder (OCD) is a heterogeneous condition that has been subtyped according to lifetime tic history [Eichstedt and Arnold, 2001; Leckman et al., 2000]. Tic-related OCD occurs more often in males than in females [Leckman et al., 1995; Mataix-Cols et al., 1999] and has an earlier age at onset than non-tic-related OCD [Leonard et al., 1992; Mataix-Cols et al., 1999]. The distinction between tic-related and non-tic-related OCD has also received support from phenomenologic, family-genetic, pharmacologic, and neuroendocrine studies [Hanna et al., 1991; Leckman et al., 1995; McDougle et al., 1994; Pauls et al., 1995].

In 70 adult OCD patients, a discriminant function analysis found that those with a chronic tic disorder had more touching, tapping, rubbing, blinking, and staring rituals, and fewer cleaning rituals, than did those without chronic tics [Holzer et al., 1994]. A similar analysis of an epidemiological sample of 40 adolescents with obsessive-compulsive spectrum disorders found that those with tics had more aggressive obsessions, whereas those without tics had more sexual obsessions [Zohar et al., 1997]. However, a set of obsessive-compulsive (OC) symptoms that distinguishes between these putative subtypes of OCD has not been identified in clinically referred children and adolescents. To test this hypothesis, we completed a discriminant function analysis with descriptive data from 60 pediatric OCD patients evaluated in two outpatient psychiatric clinics.

\footnotetext{
1Department of Psychiatry, University of Michigan, Ann Arbor, Michigan

${ }^{2}$ Department of Psychiatry and Biobehavioral Sciences, University of California at Los Angeles, Los Angeles, California

Contract grant sponsor: NIMH; Contract grant number: K20 $\mathrm{MH} 01065$.

'Dennis P. Cantwell is deceased.

*Correspondence to: Dr. Gregory L. Hanna, Department of Psychiatry, Division of Child and Adolescent Psychiatry, University of Michigan Health System, 1500 East Medical Center Drive, Ann Arbor, MI 48109-0390.
}

Received for publication 4 May 1998; Accepted 7 October 1998 


\section{METHOD}

The sample consisted of 60 children and adolescents (32 boys and 28 girls) who met DSM-III-R criteria for OCD [American Psychiatric Association, 1987]. All patients were assessed as outpatients on no medication at either the University of California, Los Angeles Medical Center or the University of Michigan Medical Center. All interviews and clinician ratings, including an assessment of lifetime obsessive-compulsive symptoms and tics, were performed by a board-certified child and adolescent psychiatrist (GLH and DPC). The exclusion criteria were 1) neurological disorder (other than tic disorder) and 2) a DSM-III-R diagnosis of mental retardation, autistic disorder, schizophrenia, or bipolar disorder. The two OCD groups consisted of 15 patients ( 6 boys and 9 girls) with a lifetime history of tics and 45 patients (26 boys, 19 girls) with no tic history.

The patients and their parents were interviewed with the Children's Yale-Brown Obsessive Compulsive Scale (CY-BOCS), a clinician rating scale for children and adolescents derived from the adult version of the scale [Goodman et al., 1989a,b; Scahill et al., 1997]. The CY-BOCS rates the severity of current OC symptoms with ten items divided equally into two subscales that rate several aspects of obsessions or compulsions. The obsession and compulsion checklists of the CY-BOCS were used to ask questions about the onset and course of 54 specific current and past OC symptoms. Categorizations of obsessions and compulsions were made according to the checklist subheadings to standardize the recording of the symptoms. Symptoms were assigned to only one obsession and/or compulsion category. Presence of a symptom was scored 1 and its absence was scored 0 .

Tics were assessed by examination and history, and characterized using the DSM-III-R definition of "involuntary, sudden, rapid, recurrent, non-rhythmic, stereotyped" motor movements or vocalizations [American Psychiatric Association, 1987]. In contrast, compulsions were defined as repetitive, but intentional types of behaviors. Tics were distinguished from "ticlike" compulsions (such as repetitive touching or blinking) based on whether the patient attached a meaning or purpose to the behavior [Holzer et al., 1994]. According to the patients and their parents, OC symptoms were the predominant clinical problem in those with a tic history. Because of the small sample size, tic history was not further dichotomized (e.g., past vs. current, motor vs. phonic, and simple vs. complex).

Statistical comparisons were done using Student's $t$ test, analysis of variance, and chi-square analysis as appropriate. Discriminant function analyses were conducted separately with seven obsession categories (contamination, aggressive, religious, saving, sexual, symmetry, and somatic) and seven compulsion categories (washing/cleaning, checking, repeating, counting, ordering, hoarding, and touching/tapping/ rubbing). Data are reported as mean \pm standard deviation. All probability values reported are two-tailed with significance stipulated as $P \leq 0.05$.

\section{RESULTS}

The subjects ranged in age from 5 to 18 years $(12.3 \pm 3.3$ years). Female subjects were significantly younger than male subjects $(11.1 \pm 3.4$ vs. $13.3 \pm 3.0$, $t=2.65, \mathrm{df}=58, P<0.02)$. As shown in Table 1 , there were no significant group differences in age, OCD onset age, or CY-BOCS symptom severity. There was no significant gender difference in tic history. Compared to those with tics, the subjects with no tic history had significantly more lifetime obsessions $(\mathrm{F}=6.01$, $\mathrm{df}=1,56, P<0.02)$ and lifetime compulsions $(\mathrm{F}=7.14$, $\mathrm{df}=1,56, P<0.01)$. Figure 1 presents the percentage of cases endorsing (score of at least 1) each of the OC symptom categories according to tic status.

Discriminant analysis of obsessions with all seven categories entered in the analysis was non-significant $(P=0.19)$. In contrast, discriminant analysis of compulsions with all seven categories entered in the analysis revealed significant discrimination of the two patient groups (Wilks' $\mathrm{l}=0.76, \chi^{2}=14.65, \mathrm{df}=7, P=0.04$ ) so that $70 \%$ of all cases were correctly classified. Table 2 summarizes the univariate $\mathrm{F}$ statistic, corresponding $P$ values, and pooled within-groups correlations for the compulsion variables. Two compulsion variables, ordering and hoarding, maximally separated the two groups (Wilks' $\lambda=0.83, \chi^{2}=10.68, \mathrm{df}=2, P=0.005$ ). Again, $70 \%$ of all cases were correctly grouped so that there was no improvement in the classification rate with the reduced set of predictor variables.

\section{DISCUSSION}

The results provide support for the hypothesis that the expression of OC symptoms in children and adolescents is influenced by lifetime tic history. Ordering, hoarding, and washing/cleaning compulsions were more common in OCD patients without tics. The percentage of subjects with tics in this sample

TABLE 1. Demographic and clinical information for 60 pediatric subjects with obsessive-compulsive disorder

\begin{tabular}{lcc} 
Variable & $\begin{array}{r}\text { OCD/tics } \\
(\mathrm{n}=15)\end{array}$ & $\begin{array}{c}\text { OC only } \\
(\mathrm{n}=45)\end{array}$ \\
\hline Sex, \% male & 40 & 58 \\
Current age, years, mean (SD) & $11.1(2.9)$ & $12.7(3.4)$ \\
OCD onset, years, mean (SD) & $8.1(3.6)$ & $9.0(3.4)$ \\
CY-BOCS total score, mean (SD) & $23.0(7.6)$ & $24.1(6.3)$ \\
CY-BOCS obsession score, mean (SD) & $10.3(5.4)$ & $11.9(3.9)$ \\
CY-BOCS compulsion score, mean (SD) & $12.7(4.4)$ & $12.2(3.7)$ \\
\hline \multicolumn{2}{c}{ No significant differences were found with the gender and OCD group } \\
comparisons.
\end{tabular}




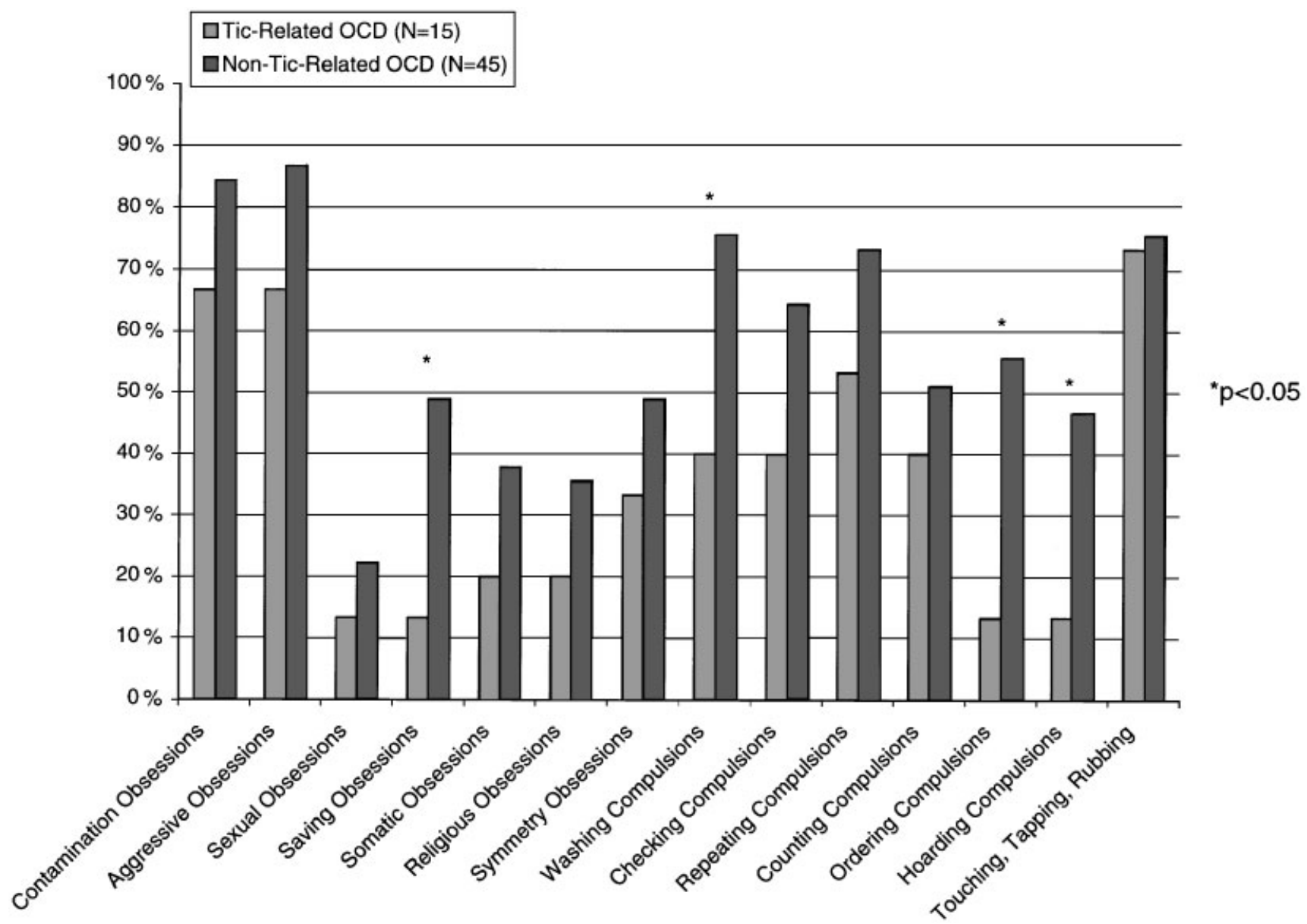

Figure 1. Types of obsessive-compulsive symptoms in OCD patients with and without tics.

TABLE 2. Discriminant function analysis of compulsion variables in 60 pediatric subjects with obsessivecompulsive disorder

\begin{tabular}{lccc} 
Name of & \multicolumn{3}{c}{ Univariate } \\
symptom category & $\mathrm{F}(1,58)$ & $P$ & $\begin{array}{c}\text { Correlation of } \\
\text { symptom variable }\end{array}$ \\
\hline Ordering & 9.06 & 0.004 & 0.71 \\
Hoarding & 5.61 & 0.021 & 0.56 \\
Washing/cleaning & 4.19 & 0.045 & 0.48 \\
Checking & 1.58 & 0.214 & 0.30 \\
Counting & 0.54 & 0.464 & 0.17 \\
Touching/tapping/rubbing & 0.35 & 0.558 & -0.14 \\
Repeating & 0.31 & 0.579 & 0.13 \\
& & & \\
$\quad$ Canonical $R$ & & & 0.48 \\
Eigenvalue & & & 0.31 \\
\hline
\end{tabular}

$(25 \%)$ is consistent with figures reported in other clinical studies of pediatric OCD [Eichstedt and Arnold, 2001; Geller et al., 1998; Hanna, 1995; Leonard et al., 1992; Riddle et al., 1990]. The results suggest that tic-related and non-tic-related OCD may be differentiated more easily in pediatric patients by compulsion categories than by obsession categories.

A previous discriminant function analysis of $\mathrm{OC}$ symptoms in adult OCD patients found that compulsion categories rather than obsession categories discriminated between the OCD subtypes and that cleaning rituals were more common in those without chronic tics [Holzer et al., 1994]. However, the study also found that OCD patients with chronic tics had more touching/blinking rituals. In a study of $\mathrm{OC}$ symptoms in OCD and Tourette's disorder, OCD patients without tics were characterized by contamination obsessions and cleaning rituals [de Groot et al., 1995]. In contrast, patients with Tourette's disorder had more sexual, symmetry, and somatic obsessions and more checking, counting, and touching/blinking compulsions. In the discriminant function analysis from that study, the differentiation between the two disorders was better with obsession categories than with compulsion categories. Similarly, in a discriminant analysis of OC symptoms in an epidemiological sample 
of adolescents, obsession categories rather than compulsion categories discriminated between the two groups [Zohar et al., 1997].

Taken together, the results from the current and previous discriminant function analyses demonstrate that there are significant differences in OC symptom expression between tic-related and non-tic-related OCD in both pediatric and adult samples. Factor analytic studies of adults with OCD have also supported the distinction between tic-related and non-tic-related OCD in symptom expression [Baer, 1994; Leckman et al., 1997; Mataix-Cols et al., 1999].

The discrepancies between some of the results from the current and previous studies may be due to differences between the samples in age, OCD onset age, and tic disorder severity as well as to differences in statistical techniques. Certain aggressive and sexual obsessions are more common in adults than in children and adolescents with OCD [Fischer et al., 1997]. Furthermore, OC symptoms may be more stable over time in adults than in youth [Mataix-Cols et al., 2002; Rettew et al., 1992]. This suggests that some differences in OC symptoms related to tic history in pediatric patients may change as those patients reach adulthood.

Previous studies have suggested that a dopaminergic dysfunction may be involved in tic-related OCD and that augmentation of a serotonergic antidepressant with a neuroleptic medication is useful for some patients with this form of OCD [Eichstedt and Arnold, 2001; Hanna et al., 1991; Leckman et al., 2000; McDougle et al., 1994]. This is consistent with the hypothesis that tic-related OCD may be associated with increased dopaminergic input in the head of the caudate, nucleus accumbens, and other portions of the ventral striatum [Eichstedt and Arnold, 2001; Leckman et al., 2000]. Smaller striatal (caudate and putamen) volumes have been observed in children with non-ticrelated OCD [Rosenberg et al., 1997]. However, a similar study has not been done in children with ticrelated OCD.

The limitations of the present study require further consideration. The sample size of the tic-related OCD group was small and precluded analysis according to specific tic disorders. Data on OC symptom age of onset, tic severity, and other comorbid conditions were missing for some subjects. Patients were assigned to the tic-related OCD group based only on their personal history of tic symptoms. However, it may be necessary to base that assignment on family history as well as personal history because some forms of OCD may be related etiologically (and perhaps genetically) to Tourette's disorder [Pauls et al., 1995]. It may be important, therefore, to examine the differences in OC symptoms between these putative subtypes of OCD with data from a family study of OCD that rigorously assesses OC symptoms and tics in all first-degree relatives. Finally, as suggested by a recent report, the distinction between tic-related and non-tic-related OCD may be useful in molecular genetic studies of OCD [Cavallini et al., 2002].

\section{REFERENCES}

American Psychiatric Association. 1987. Diagnostic and statistical manual for mental disorders, 3rd edition, revised. Washington, DC: American Psychiatric Press.

Baer L. 1994. Factor analysis of symptom subtypes of obsessive compulsive disorder and their relation to personality and tic disorders. J Clin Psychiatry 55:18-23.

Cavallini MC, Di Bella D, Siliprandi F, Malchiodi F, Bellodi L. 2002. Exploratory factor analysis of obsessive-compulsive patients and association with 5-HTTLPR polymorphism. Am J Med Genetics 144:347-353.

de Groot CM, Bornstein RA, Janus MD, Mavissakalian MR. 1995. Patterns of obsessive compulsive symptoms in Tourette subjects are independent of severity. Anxiety 1:268-274.

Eichstedt JA, Arnold SL. 2001. Childhood-onset obsessive-compulsive disorder: a tic-related subtype of OCD? Clin Psychol Rev 21:137-158.

Fischer DJ, Himle JA, Hanna GL. 1997. Age and gender effects on obsessive-compulsive symptoms in children and adults. Depression Anxiety 4:237-239.

Geller DA, Biederman J, Jones J, Park K, Schwartz S, Shapiro S, Coffey B. 1998. Is juvenile obsessive-compulsive disorder a developmental subtype of the disorder? A review of the pediatric literature. J Am Acad Child Adolesc Psychiatry 37:420-427.

Goodman WK, Price LH, Rasmussen SA, Mazure C, Fleischmann RL, Hill CL, Heninger GR, Charney DS. 1989a. The Yale-Brown Obsessive Compulsive Scale I: development, use, and reliability. Arch Gen Psychiatry 46:1006-1011.

Goodman, WK, Price, LH, Rasmussen, SA, Mazure, C, Delgado P, Heninger GR, Charney, DS. 1989b. The Yale-Brown Obsessive Compulsive Scale II: validity. Arch Gen Psychiatry 46:1012-1018.

Hanna GL, McCracken JT, Cantwell DP. 1991. Prolactin in childhood obsessive-compulsive disorder: clinical correlates and response to clomipramine. J Am Acad Child Adolesc Psychiatry 30:173-178.

Hanna GL. 1995. Demographic and clinical features of obsessivecompulsive disorder in children and adolescents. J Am Acad Child Adolesc Psychiatry 34:19-27.

Holzer JC, Goodman WK, McDougle CJ, Baer L, Boyarsky BK, Leckman JF, Price LH. 1994. Obsessive-compulsive disorder with and without a chronic tic disorder. Br J Psychiatry 164:469-473.

Leckman JF, Grice DE, Barr LC, de Vries ALC, Martin C, Cohen DJ, McDougle CJ, Goodman WK, Rasmussen SA. 1995. Ticrelated vs. non-tic related obsessive compulsive disorder. Anxiety $1: 208-215$.

Leckman JF, Grice DE, Boardman, J, Zhang H, Vitale A, Bondi C, Alsobrook, J, Peterson BS, Cohen DJ, Rasmussen SA, Goodman WK, McDougle CJ, Pauls DL. 1997. Symptoms of obsessive compulsive disorder. Am J Psychiatry 154:911-917.

Leckman JF, McDougle CJ, Pauls DL, Peterson BS, Grice DE, King RA, Scahill L, Price LH, Rasmussen SA. 2000. Tic-related versus non-tic-related obsessive-compulsive disorder. In: Goodman WK, Rudorfer MW, Maser JD, editors. Obsessive-compulsive disorder: contemporary issues in treatment. Mahwah, NJ: Lawrence Erlbaum Associates. p 43-68.

Leonard HL, Lenane MC, Swedo SE, Rettew DC, Gershon ES, Rapoport JL. 1992. Tic and Tourette's disorder: a 2- to 7-year follow-up of 54 obsessive-compulsive children. Am J Psychiatry 149:1244-1251. 
Mataix-Cols D, Rauch SL, Manzo P, Jenike M, Baer L. 1999. Use of factor-analyzed symptom dimensions to predict outcome with serotonin reuptake inhibitors and placebo in the treatment of obsessive-compulsive disorder. Am J Psychiatry 156:1409-1416.

Mataix-Cols D, Rauch SL, Eisen JL, Shera DM, Goodman WK, Rasmussen SA, Jenike MA. 2002. Symptom stability in adult obsessive-compulsive disorder: Data from a naturalistic two-year follow-up study. Am J Psychiatry 159:263-268.

McDougle CJ, Goodman WK, Leckman JF, Lee NC, Heninger GR, Price LH. 1994. Haloperidol addition in fluvoxamine-refractory obsessive-compulsive disorder: A double-blind, placebo-controlled study in patients with and without tics. Arch Gen Psychiatry 51:302-308.

Pauls DL, Alsobrook JP, Goodman W, Rasmussen S, Leckman JF. 1995. A family study of obsessive-compulsive disorder. Am J Psychiatry 152:76-84.

Rettew DC, Swedo SE, Leonard HL, Lenane MC, Rapoport JL. 1992. Obsessions and compulsions across time in 79 children and adolescents with obsessive-compulsive disorder. J Am Acad Child Adolesc Psychiatry 31:1050-1056.

Riddle MA, Scahill L, King R, Hardin MT, Towbin KE, Ort SI, Leckman JF, Cohen DJ. 1990. Obsessive-compulsive disorder in children and adolescents: phenomenology and family history. J Am Acad Child Adolesc Psychiatry 29:766-772.

Rosenberg DR, Keshavan MS, O'Hearn KM, Dick EL, Bagwell WW, Seymour AB, Montrose DM, Pierri JN, Birmaher B. 1997. Frontostriatal measurement in treatment-naïve children with obsessive-compulsive disorder. Arch Gen Psychiatry 54:824-830.

Scahill L, Riddle MA, McSwiggin-Hardin M, Ort SI, King RA, Goodman WK, Cicchetti D, Leckman JF. 1997. Children's YaleBrown Obsessive Compulsive Scale: reliability and validity. J Am Acad Child Adolesc Psychiatry 36:844-852.

Zohar AH, Pauls DL, Ratzoni G, Apter A, Dycian A, Binder M, King R, Leckman JF, Kron S, Cohen DJ. 1997. Obsessive-compulsive disorder with and without tics in an epidemiological sample of adolescents. Am J Psychiatry 154:274-276. 